\title{
A pintura como paradigma da percepção
}

\author{
Ericson Falabretti \\ efalabretti@gmail.com \\ PUC-PR, Curitiba, Paraná, Brasil
}

resumo As reflexões sobre a pintura atravessam todo o itinerário da obra de Merleau-Ponty e parecem indicar os motivos do movimento e da unidade do seu pensamento, especialmente quando buscamos compreender o alcance significativo da percepção enquanto um acontecimento pré-reflexivo. A experiência da percepção é radicalizada na pintura que expressa um "nível primordial" - "leva à sua última potência um delírio que é a visão mesma" - com todos os caracteres que a própria fenomenologia buscou atingir ao descrever as diferentes formas de experiência perceptiva, seja através da descrição da experiência pré-reflexiva do corpo próprio ou, finalmente, da concepção de fé perceptiva enquanto "doação em carne". A pintura realiza a intenção mais genuína de uma filosofia dedicada à descrição do pré-reflexivo: testemunha e interroga o ser. 0 pintor, como indicam as análises sobre Cézanne, ao permanecer no solo originário, sem a necessidade de justificativas ou de fundamentos, livre da obrigação de anunciar uma tese ou uma convenção sobre o mundo, expressa a significação mais bruta da percepção: aquilo que faz do visível ser visível.

palavras-chave Percepção; Pintura; Corpo; Expressão.

Uma filosofia do recuo. Primeiro em direção ao irrefletido, depois ao campo do silêncio e, finalmente, ao tecido invisível. Essa parece ser a lógica da filosofia merleau-pontyana; uma chave de interpretação da sua obra repetida por boa parte da crítica especializada. Em cada recuo o que se vê é o esforço para alcançar e expressar o sentido original do ser no mundo;

Recebido em 20 de dezembro de 2011. Aceito em 21 de fevereiro de 2012.

doispontos, Curitiba, São Carlos, vol. 9, n. 1, p.201-226, abril, 2012 
o núcleo capaz de explicar a ambiguidade do perceber e do dizer e, finalmente, de dissolver a distinção entre o em si e o para si. Enquanto a volta ao irrefletido procurou desvelar o "logos" primitivo do nosso contanto com o mundo e com o outro, o recuo ao campo do silêncio investigou a modulação estrutural da linguagem que precede o uso empírico da fala para, então, abrir caminho ao invisível. Esse último recuo - ato derradeiro de um pensamento inacabado - realizou a passagem do corpo próprio uma presença no mundo - para a carne do mundo, existência como inerência quiasmática com as coisas, com o outro e com o mundo.

Em A Estrutura do Comportamento e na Fenomenologia da percepção esse recuo pode ser descrito como o ato inaugural de uma onto-fenomenologia, uma redução à existência carnal do sujeito e ao fundo primitivo da percepção. Desde $A$ Estrutura do Comportamento, uma ideia que foi sendo sistematicamente aprofundada na Fenomenologia da percepção e radicalizada em O Visível e o invisível, Merleau-Ponty já havia superado o objetivismo herdado das teorias mecanicistas sobre o corpo e estabelecido o poder criativo e não constituinte da percepção a partir da sua forma dialética. A percepção - uma experiência pré-reflexiva - apreende um sentido estrutural que não existe a priori no sujeito ou no mundo. Ela opera num sistema de trocas em que os caracteres do mundo - os seus vetores sensíveis - são vividos como modulações no corpo, assim como as intenções do corpo são acolhidas pelas próprias coisas, pois elas silenciosamente se abrem e se comunicam com o corpo em movimento. Essa perspectiva sobre a percepção como um acontecimento nascido, ao mesmo tempo, do corpo e do mundo pode ser lida na bela passagem da Estrutura do Comportamento sobre a experiência perceptiva vivida no campo de futebol:

O campo de futebol não é, para o jogador em ação, um "objeto", ou seja, a palavra ideal que pode dar lugar a multiplicidade indefinida de vistas perspectivas e permanecer equivalente sob essas transformações aparentes. É percorrido por linhas de força (as linhas laterais, as que limitam a meia lua), articulado em setores (por exemplo, os buracos entre os adversários) que impõe certo modo de ação, a desencadeiam e exigem como à revelia do jogador. O campo não lhe é dado, mas está presente para ele como termo imanente das suas intenções práticas, ele e o jogador são um só corpo e o jogador sente, por exemplo, a direção do 
gol tão imediatamente quanto a vertical e a horizontal de seu próprio corpo. ( MERLEAU-PONTY 1972, p. 263)

Esse sistema de trocas - essa constituição dialética da percepção - é o que permitiu a Merleau-Ponty superar as alternativas antitéticas excludentes e afirmar que a percepção não se reduz ao viés noético (função do sujeito) ou, ainda, ao viés noemático (do objeto). As linhas e os espaços do campo, juntamente com as intenções práticas do corpo formam "um só corpo". As direções do campo de futebol não operam sobre o jogador como, inversamente, não são definidas a partir do jogador. Entre o corpo e o campo de futebol o que se estabelece é uma comunicação anônima, estrutural e anterior a toda atividade cognoscente. Na Fenomenologia da percepção, Merleau-Ponty aprofundou a experiência pré-reflexiva e a tese da percepção. No lugar do "eu puro" e da sua antítese empirista - o corpo objetivo - o filósofo descreveu a potência criativa do corpo próprio e a sua meditação nascida do contato com o mundo. A visão, o movimento, a sexualidade e a fala, por exemplo, são vivências do corpo próprio que estão na origem da percepção e de todas as formas de comunição. O corpo próprio não reage de maneira reflexa a um estímulo, ele o acolhe e reelabora as solicitações do mundo conforme estava preparado para recebê-las e modificá-las. Da visão, do movimento e da sexualidade do corpo próprio brota uma intencionalidade originária e operante, uma meditação naturada (encarnada) e naturante (livre):

A teoria do esquema corporal é implicitamente uma teoria da percepção. Nós reaprendemos a sentir nosso corpo, reencontramos, sob o saber objetivo e distante do corpo, este outro saber que temos dele porque ele está sempre conosco e porque nós somos corpo. Da mesma maneira, será preciso despertar a experiência do mundo tal como ele nos aparece enquanto estamos no mundo por nosso corpo, enquanto percebemos o mundo com nosso corpo. Mas, retomando assim o contato com o corpo e com o mundo, é também a nós mesmos que iremos reencontrar, já que, se percebemos com nosso corpo, o corpo é um eu natural e como que o sujeito da percepção. (MERLEAUPONTY 1999, p. 278) 


\section{4}

Depois de estabelecer a experiência do corpo próprio como fundamento da unidade do ser no mundo, a inflexão ao fundo bruto, agora na fase intermediária da obra merleau-pontyana, está orientada para uma verdade que antecede e sustenta todos os modos de expressão do cogito tácito: a forma pura da linguagem. No texto A linguagem indireta $e$ as vozes do silêncio, Merleau-Ponty faz uma distinção entre o uso empírico e o uso criador da linguagem. O uso empírico - uma modulação da linguagem em segunda potência - nasceu dessa primeira face muda e articulada da linguagem.

A expressividade primitiva está em uma linguagem que remonta a uma estruturação original dos signos, em um sistema de articulação fonética de sentido que antecede o uso dos signos e a própria fala. A língua - como também a arquitetura, a pintura, a literatura - está inscrita e antecipada nesse tecido original de expressão, nessa estrutura muda que parece nutrir todas as formas de comunicação de um sentido inicial. A estruturação dos signos é o fundo que alimenta a fala empírica e permite a criança, por exemplo, falar muito antes de compreender como se aplica diversamente o princípio da palavra: "Mesmo quando é possível datar a emergência de um princípio para si, este estava antes presente na cultura a título de obsessão ou de antecipação, e a tomada de consciência que o coloca como significação explícita apenas lhe completa a longa incubação num sentido operante.” (MERLEAU-PONTY 2004b, p. 70) Esse sentido estrutural, essa ordem original, numa perspectiva inversa de uma interpretação atomista, explica o modo como os signos se diferenciam e, também, formam a linguagem criadora. Os signos isolados conforme a interpretação merleau-pontyana de Saussure - nada significam e deles, nessa condição, não se pode inferir a existência de nenhuma forma de linguagem: "Se o signo só quer dizer algo na medida em que se destaca dos outros signos, seu sentido está totalmente envolvido na linguagem, a palavra intervém sempre sobre um fundo de palavra, nunca é senão uma dobra no imenso tecido da fala." (MERLEAU-PONTY 2004b, p. 71).

Não encontramos o sentido da linguagem constituindo pontos de referência no mundo, supondo um sistema de equivalências entre o mundo, o pensamento e a articulação dos signos. Encontramos o sentido da linguagem na própria linguagem, na sua articulação interna, na sua 
estrutura figurativa que antecede a própria fala:“... a linguagem não pressupõe a sua tabela de correspondência, ela mesma desvela os seus segredos, ensina-os a todas as crianças que vem ao mundo, é inteiramente mostração.” (MERLEAU-PONTY 2004b, p.72).

O uso empírico da linguagem, uma potência expressiva derivada dessa existência interior é, nos diz Merleau-Ponty citando Mallarmé, "a moeda gasta que colocam em silêncio na minha mão.” (MERLEAU-PONTY 2004b, p.73) Desconsiderando a ideia da linguagem como tradução de um pensamento - um texto original - toda linguagem é indireta, alusiva e conserva um fundo silencioso, não há expressão empírica completa. Primeiro, o sentido da palavra não corresponde, ponto por ponto, às partes do sinal ${ }^{1}$ e, depois, a linguagem significa - diz um sentido - quando, em vez de traduzir o pensamento ou, ainda, figurar a percepção e o próprio mundo, deixa-se fazer e refazer por essa experiência. Nessa direção, a origem da unidade expressiva da linguagem está na linguagem primitiva e silenciosa - no seu uso criador - e podemos dizer sobre a linguagem, inspirando na fala de Merleau-Ponty sobre a filosofia, que pensar sobre a linguagem é abrir-se a um horizonte de sentidos muito mais rico do que aquele que a nossa fala pode atingir e significar.

No final dos anos 50, nos cursos sobre o conceito de Natureza, no escrito Por toda parte e em nenhuma parte, no O ensaio sobre o filósofo e sua sombra e, mais explicitamente, no Visível e Invisível, Merleau-Ponty realiza o recuo mais radical, quer voltar ao grau último da realidade e ultrapassar todas as clivagens ontológicas que separam o percepiente e o percebido, o falante e a fala, o sentiente e o sentido. Na primeira nota de trabalho do Visível e o invisível - Janeiro de 1959 - o filósofo aponta pelo menos uma das razões desse último recuo: "a crise na filosofia nunca foi tão radical e, por isso mesmo, é necessário um retorno à ontologia. A interrogação ontológica e suas manifestações: a questão sujeito-objeto, a questão da intersubjetividade; a questão da natureza." (MERLEAU-PONTY 2000, p.163). No Visível e o invisível a marca desse recuo está na abertura de um campo que não se manifesta como sucessão temporal ou fronteira espacial. Recuo a um tecido atópico e acrônico, que não é um ali ou um antes, mas envolve e está diluído entre o percebido, o falado e o visível: "A abertura para o mundo supõe que o mundo seja e permaneça horizonte, não porque minha visão o faça recuar além dela mesma, mas 
porque de alguma maneira, aquele que vê pertence-lhe e está nele instalado." (MERLEAU-PONTY 2000, p. 101)

Como encontramos na leitura de Barbaras - artigo Les trois sens de la chair: sur une impasse de l'ontologie de Merleau-Ponty - foi na filosofia husserliana que Merleau-Ponty encontrou as noções de corpo objetivo e de corpo vivo e, posteriormente, conferiu um caráter ontogênico e filosófico ao segundo sentido. Husserl, em Ideias II, designa Leib - em oposição a Körper - como corpo vivo e sensível, aquele que eu habito e, por isso mesmo, um corpo que não se reduz ao atomismo material das coisas. O corpo vivo e sensível - Leib - é corpo sentiente-sentido, da experiência da reversibilidade, da mão que toca e é tocada.

Ao retomar essa distinção husserliana - entre Leib e Körper - MerleauPonty realizou passagem do corpo próprio para a noção de carne do mundo. Mais do que um sistema de trocas e equivalências, o que encontramos é a tessitura comum estabelecida pelo sentir entre o corpo próprio e a carne do mundo. A relação entre o jogador e o campo de futebol deixa, nesse momento, de ser um fenômeno entre o corpo e o mundo e passa ser concebida como experiência de uma única carne, pois ambos estão envolvidos em único tecido. No Visível e o invisível a carne chair - torna-se o conceito principal de uma nova ontologia fundada na experiência do sentiente-sentido:

O que chamamos de carne, essa massa interiormente trabalhada, não tem, portanto, nome em filosofia alguma. Meio formador do objeto e do sujeito, não é o átomo de ser, o em si duro que reside num lugar e num momento únicos.... É preciso pensar a carne, não a partir das substâncias, corpo, espírito, pois seria então união dos contraditórios, mas, dizíamos, como elemento, emblema concreto de uma maneira de ser geral. (MERLEAU-PONTY 2000. p. 142).

Portanto entre o primeiro recuo - a descoberta do corpo próprio - e o último - a carne do mundo - Merleau-Ponty descobriu uma ligação que nos deu acesso ao sentido bruto do ser, ao dado primeiro que escapa às antinomias: consciência-natureza; corpo-alma; transcendentalempírico. 
Todavia, esse movimento final - o último recuo - comporta dois problemas: um de fundamentação ontológica e outro de expressividade. $\mathrm{O}$ primeiro, identificado por Barbaras no texto já citado, está na passagem de um conceito ôntico (corpo próprio) para um conceito ontológico (carne do mundo), da reversibilidade experimentada no corpo para a reversibilidade na carne do mundo. A ligação estabelecida entre o sistema de equivalências do corpo próprio para a carne do mundo reproduz, à primeira vista, o mesmo expediente que Merleau-Ponty acusou nas filosofias de Descartes e Kant. O corpo próprio - semelhante ao sujeito das Meditações Metafísicas - operaria como um cogito constituinte encontrando no mundo e nas coisas significações nascidas no próprio eu. Entre o percebido e o sentido, entre o corpo e a carne do mundo há um ponto de ruptura, uma espécie de fissura ontológica que sugere uma passagem como atividade constituinte, nas palavras de Barbaras, "curvatura do cogito no mundo".

Como o próprio Barbaras indica, Merleau-Ponty respondeu no Visível e o invisivel a essa passagem da subjetividade para a ontologia. Antes de tudo, é preciso esquecer a noção passagem - do ôntico para o ontológico - e recuperar a ideia de entrelaçamento. Esse conceito, como é apresentado por Carbone, é mais do que um sistema de equivalências presentes no corpo próprio e no mundo, "é a reabilitação ontológica do sensível." O entrelaçamento supõe que a carne do sujeito, a sua condição sentiente-sentido, como testemunha ontológica de uma dimensão original que a excede e da qual ela é apenas uma modalidade privilegiada: a carne do mundo.

Na Fenomenologia da percepção, conforme interpreta Carbone, a experiência da mão que toca e da mão tocada, mostrou como o corpo próprio é integralmente comunicação, relação carnal com o mundo, realizando-se como pensamento imediato do sensível. Com a intenção de garantir ao corpo próprio um estatuto diferente da objetificação operada pela Psicologia clássica, Merleau-Ponty trabalhou com a ideia de que o corpo próprio não é nem tangível e nem visível na mesma medida em que ele é o que vê e o que ele toca: "O corpo surpreende-se a si mesmo do exterior prestes a exercer uma função de conhecimento, ele tenta 
tocar-se tocando, ele esboça um tipo de reflexão, e bastaria dizer que "tocam" meu corpo, mas apenas quando ele está inerte, e portanto sem que eles o surpreendam em sua função exploradora (MERLEAUPONTY, 1998, p.137)." O corpo próprio, diferente de uma coisa, permanece sempre presente sem nunca estar completamente diante de nós; continua misteriosamente inexplorado e, ao mesmo tempo, perspectivamente invariante; apresenta-se ambiguamente como sentiente e, na mesma situação, como sentido.

Em O Visivel e o invisivel, a experiência das sensações duplas manifesta uma nova possibilidade. Se o corpo na Fenomenologia da percepção deixou de ser um objeto entre os objetos, em O Visível e o invisível ele não é mais pensando no horizonte de uma filosofia da subjetividade. É possível encontrar nos corpos, no mundo, no outro uma espécie de deiscência abertura das coisas ao sentiente-sentido - como se as coisas que toco e sinto, simultaneamente, realizassem em mim o tocar e o sentir. O corpo abre-se em dois, deixa de ser aquele que percebe e sente para, também, ser percebido e sentido. Como está na última parte de OVisível e o invisível - O entrelaçamento, o quiasma - entre a mão que toca e aquela que é tocada, entre o corpo e o mundo não existe passagem, mas abertura e invasão, as coisas se entranham no corpo e, também, o corpo nas coisas:

O que significa que cada visão monocular, cada palpação de uma única mão, embora tenha seu visível e seu tangível, esta ligada à outra visão, à outra palpação, de modo a realizar com elas a experiência de um único corpo diante de um único mundo, graças a uma possibilidade de reversão, de reconversão de sua linguagem na delas, possibilidade de reportar e de revirar segundo a qual o pequeno mundo privado de cada um não se justapõe àquele de todos os outros mas é por ele envolvido, colhido dele, constituindo, todos juntos, um sentiente em geral, diante de um Sensível em geral. Ora, essa generalidade que faz a unidade de meu corpo, por que não se abriria ela a outros corpos? $\mathrm{O}$ aperto de mãos também é reversível, posso sentir-me tocado ao mesmo tempo que toco e, por certo, não existe um grande animal de que nossos corpos sejam os órgãos, como as mãos, os olhos o são cada um deles. Por que não existiria a sinergia entre diferentes organismos, já que é possível no interior de cada um? Suas paisagens se cruzam, suas ações e suas paixões se ajustam exatamente: isto é possível desde que se 
pare de definir primordialmente o sentir pela pertença à mesma

"consciência", compreendendo-o, ao contrário, como retorno sobre si no visível, aderência carnal do sentiente ao sentido e do sentido ao sentiente. Porquanto recobrimento e fissão, identidade e diferença, essa aderência faz brotar um raio de luz natural que ilumina toda a carne, não apenas a minha. (MERLEAU-PONTY 2000, p.138)

Em virtude dessa deiscência - fissão e identificação - os corpos, as coisas e outro se revelam sentiente-sentido. Em O Visível e Invisível o entrecruzamento sentiente-sentido - entre a mão tocante e a coisa tocada - é simultâneo, espacialmente e temporalmente. No fenômeno da reversibilidade, como interpreta Carbone, está em evidência a "função exploradora do objeto" que corresponde à carne do sensível. Sujeito e objeto estão fundidos e, do mesmo modo, atividade e passividade estão acoplados: "os corpos escapam da distinção entre sujeito e objeto, as coisas igualmente, na medida em que estão inserida no mesmo tecido intencional que os corpos" (CARBONE 2001, p. 93).

A reflexão sobre a intersubjetividade segue o mesmo caminho. $\mathrm{O}$ outro deixou de ser aquela pessoa que figura na paisagem dos meus projetos e está integrado ao tecido da minha carne. Ambos, eu e o outro, compomos uma intercorporalidade, pois não é a introspecção mas, sobretudo, uma experiência estesiológica, prefigurada na experiência da mão que toca e é tocada que faz com que a presença do outro seja indissociavelmente como de um "ser sensível, de coexistência, de coimplicação e de copercepção, presente como intersubjetividade e como intercorporeidade." (CARBONE 2001, p. 93). Entre o eu e o outro, entre sujeito e objeto, entre passividade e atividade, na dimensão do sensível, não há qualquer distinção de natureza reflexiva, eles participam um do outro. Além disso, mais do que um índice de familiaridade entre o corpo, as coisas e o outro o que encontramos é a continuidade e o entrecruzamento tecido pelo sentir: a carne do mundo.

Em OVisível e o invisível o problema da expressão permanece, de certo modo, aberto; sobretudo enquanto a filosofia procura uma linguagem que espelhe esse mundo primitivo de puro sentir. Em uma nota de trabalho fevereiro de 1959 - Merleau-Ponty reavalia o alcance do capítulo sobre o Cogito na Fenomenologia da percepção. Indica que o cogito desvinculado 


\section{0}

da fala deixou em aberto "o problema da passagem do sentido perceptivo ao sentido referente à linguagem, do comportamento à tematização" (MERLEAU-PONTY 2000, p.171). Além disso, conforme já havia sido comentado em $A$ Linguagem indireta $e$ as vozes do silêncio, falar sobre o irrefletido é contaminá-lo com a palavra em segunda potência. Portanto, a questão que se coloca, considerando o estatuto que Merleau-Ponty conferiu ao uso empírico da linguagem, se refere à possibilidade de uma expressão, de um discurso sobre a carne do mundo. "O filósofo fala" nos diz Merleau-Ponty na sua última obra - isto porém nele é uma fraqueza e uma fraqueza inexplicável: devia calar-se, coincidir em silêncio e encontrar no Ser uma filosofia já feita" (MERLEAU-PONTY 2000, $\mathrm{p}$ 123). Além do mais, a fala silenciosa, o sentido bruto articulado pelos signos como foi estabelecido em $A$ linguagem indireta - o único a coincidir com o Ser - não é o avesso da linguagem enfraquecida, do uso empírico e, porque não, filosófico da linguagem? O que nos propomos a discutir é como esse sentido bruto do ser no mundo, a face amorfa e indistinta da carne do mundo, consagrada ao silêncio do filósofo, pode encontrar na realização pictural a sua melhor expressão.

\section{III- A solução estética}

As análises sobre a pintura ${ }^{2}$, e mais especificamente o trabalho do pintor, acompanham o deslocamento da obra merleau-pontyana. Referências sobre a pintura são encontradas em quase a totalidade dos seus textos, geralmente para dizer o que na filosofia não tem palavras. $\mathrm{Na}$ discussão sobre a pintura, particularmente da obra de Cézanne, Merleau-Ponty parece ter encontrado a realização do objetivo fundamental da sua própria filosofia. Em A Dúvida de Cézanne, por exemplo, Merleau-Ponty investiga o nascimento de um logos primordial fundido e, ao mesmo tempo, revelador da experiência sensível: “...o gênio de Cézanne é fazer as deformações perspectivas... para dar a impressão de uma ordem nascente, de um objeto em via de aparecer, em via de aglomerar-se sob o nosso olhar." (MERLEAU-PONTY 2004c, p.129) Em A linguagem indireta $e$ as vozes do silêncio ${ }^{3}$ são apresentados os elementos picturais da linguagem com o objetivo de descobrir a face surda, visível e tátil da 
linguagem e, num sentido contrário, também são desvendados os traços de musicalidade presentes na pintura. As modulações sonoras das cores, dos desenhos, das linhas e da paisagem, enfim, todos os elementos da linguagem oral possíveis de serem encontrados nos quadros: "Comecemos por compreender que a há uma linguagem tácita e que a pintura fala a seu modo" (MERLEAU-PONTY 2004, p.76). Finalmente, em O Otho e o espírito a ligação entre filosofia e estética - como observa Carbone se organiza em torno de uma questão que ocupa um lugar central em todo o pensamento de Merleau-Ponty: “a problemática relação entre o mundo perceptivo amorfo e a sua expressão" (CARBONE 2001, p.87). Nessa perspectiva, no exame do itinerário das obras estéticas de MerleauPonty é possível encontrar a discussão do sentido latente da nossa experiência direta - primeira - e da força expressiva da camada mais original do ser no mundo.

Porém, como a pintura é capaz de figurar a relação entre a percepção e o mundo e, ainda, expressar o sentido primeiro do ser no mundo? A pintura realiza, desde o início, um único movimento, um único recuo em direção à carne do mundo. Na pintura as experiências do perceber e do mostrar - do sentiente-sentido - estão reunidas, ao mesmo tempo, nas diferentes formas de reflexão carnal: ver, tocar. A percepção, conforme já foi estabelecida anteriormente, não é uma atividade cognitiva que reúne dados dispersos para formar uma ideia, não é uma função segunda do intelecto constituída pela associação de sensações que precisa ser corrigida pelo pensamento. Desdobrada no corpo próprio a percepção pré-existe à reflexão e alcança o sentido das coisas e do mundo como uma estrutura dotada de uma significação unívoca e, ao mesmo tempo, aberta: "O mundo não é aquilo que eu penso, mas aquilo que eu vivo; eu estou aberto ao mundo, comunicome indubitavelmente com ele, mas não o possuo, ele é inesgotável." (MERLEAU-PONTY 1999, p.14) Portanto, a percepção é uma vivência sobre a verdade do mundo, porém uma verdade que não pode ser tomada como acabada, pois ao mesmo tempo em que nos dá "acesso ao sentido das coisas" também deixa fendido um horizonte de significações. A certeza que experimentamos na percepção vem sempre acompanhada de um sentimento perturbador: um êxtase de que há mais coisas para ver e para descobrir. 
A situação do sujeito no mundo está na base dessa condição ambígua da percepção. Essa situação, caracterizada por Merleau-Ponty como uma presença capaz de uma reflexão corpórea é, pode-se dizer, uma experiência estética. Nesse caso, apesar de muito próximo das teses kantianas da Terceira Crítica, a experiência estética em Merleau-Ponty, assentada no corpo próprio, não se coloca entre as alternativas de um juízo estético puro ou de um juízo de gosto, é apreensão de um sentido estrutural no qual o belo é apenas uma das suas faces. Na Fenomenologia da percepção é a consciência da presença do corpo próprio, do seu enraizamento no mundo, do seu movimento e das suas vivências que torna possível formar com o mundo um sistema no qual toda percepção seja sempre uma percepção de um sentido determinado e, ao mesmo tempo, aberto. $\mathrm{O}$ significado de uma cor antes de ser elaborado e fixado pelo pensamento é vivido e preparado no corpo. O azul, conforme o exemplo de MerleauPonty, antes de significar paz já se instala e se comunica com o corpo do sujeito, já encontra nele um correlato da paz. Toda reflexão sobre o azul é antecipada no corpo próprio, é sentida integralmente na carne: "Meus músculos relaxam, o olho se acomoda e sou concomitantemente invadido pela paz. A sensação é literalmente uma comunhão." (MERLEAUPONTY 1999, p. 286)

A concepção da experiência perceptiva como estética está assentada na fixação da vida percepto-corporal, no modo como essa vida é integralmente apreensão de sentido. Merleau-Ponty, primeiramente na Fenomenologia da Percepção, desvela o âmbito estrutural da existência encarnada. Mostra que o enraizamento do sujeito no mundo revela uma subjetividade mais ampla do que aquela estabelecida pela filosofia intelectualista, pois se refere a uma organização impessoal, há um esquema corporal que apreende o sentido das coisas a partir de um campo perceptivo sobre o fundo do mundo. As coisas se apresentam para a percepção não como um mosaico de qualidades, mas como uma configuração total, resultado de uma experiência não tética, pré-objetiva e sensível. O corpo próprio realiza uma síntese perceptiva totalmente diferente da síntese intelectual. No processo de percepção do corpo próprio não há autopercepção no sentido de voltar a si mesmo como está dado na filosofia intelectualista. A síntese realizada no corpo é antepredicativa e é da ordem do sentir: "Aquele que percebe não está desdobrado diante de si 
mesmo como uma consciência deve estar (...) Na percepção nos não pensamos o objeto e não nos pensamos pensando-o..." (MERLEAUPONTY 2004c, p.320). Entretanto, a radicalização dessa vivência estética pré-consciente, fundamentalmente corporal, bem como a sua face mais expressiva, pode ser localizada na pintura, agora não apenas como experiência estética, mas, fundamentalmente, como expressão estética:

A expressão estética confere a existência em si àquilo que exprime, instala-o na natureza como uma coisa percebida acessível a todos ou, inversamente, arranca os próprios signos - a pessoa do ator, as cores e a tela do pintor - de sua existência empírica e os arrebata para um outro mundo. (MERLEAU-PONTY 1999, p.248)

A relação entre o enraizamento do sujeito no mundo e a expressividade estética encontra o seu melhor exemplo na situação do pintor e na sua obra. A fórmula da experiência estética - pensar a partir do corpo e exprimir-se com os signos do corpo - permite à pintura reconduzir a expressividade ao núcleo original das coisas. Como já está dado na Fenomenologia da percepção, na pintura transparece a potência criadora do corpo próprio. O emprego indissociável da visão e do tato, fundamento da expressividade pictórica, recria e reconstitui o mundo perceptivo, pois é passível de encontrar em cada coisa, em cada paisagem o sentido latente da totalidade:

Cézanne dizia de um retrato: "Se pinto todos os pequenos azuis e todos os pequenos marrons, eu o faço olhar como ele olha... Ao diabo se eles desconfiam como, casando um verde matizado com um vermelho, se entristece uma boca ou se faz uma face sorrir." Essa revelação de um sentido imanente ou nascente no corpo vivo se estende, como o veremos, a todo o mundo sensível, e nosso olhar, advertido pela experiência do corpo próprio, reencontrará em todos os outros "objetos" o milagre da expressão. Em Peau de Chagrin, Balzac descreve "uma toalha de mesa branca como uma camada de neve recentemente caída e na qual se dispunham simetricamente os talheres, coroados por pequenos pães dourados". "Durante toda a minha juventude", dizia Cézanne, "eu quis pintar isso, essa toalha de neve fresca... Agora eu sei que só se deve querer pintar: se se dispunham simetricamente os talheres e os pequenos pães dourados e eu os pinto 


\section{4}

coroados, estou perdido, você compreende? E, se verdadeiramente eu harmonizo e matizo meus talheres e meus pães como no modelo natural, esteja certo de que as coroas, a neve e todo o tremor estarão ali." O problema do mundo, e, para começar, o do corpo próprio, consiste no fato de que tudo reside ali. (MERLEAU-PONTY 1999, p.268).

Sempre próximo à natureza, como é caso de Cézanne, a pintura, comenta Merleau-Ponty no ensaio dos anos 40, quer restaurar a nossa percepção originária, fazer as coisas falarem a partir da sua língua natural, quer reunir o que a ciência separou: o desenho e a cor, a sensação e o julgamento, a visão e a estrutura do mundo.

A análise da pintura, antes de tudo, exige que se recupere o trabalho e a situação do pintor livre de todo pré-conceito psicologista. MerleauPonty retomou a vida de Cézanne para dizer que ela não explica a sua obra. O medo da morte, a desconfiança do outro, a necessidade de solidão, as hesitações diante do pai não se sobrepõem aos motivos da natureza e ao sentido que nasce da contemplação dos seus quadros. Em $A$ Dúvida de Cézanne, como também nos ensaios posteriores, se o entendimento da obra de arte não pode ser determinado pela sua vida, também não está na influência da história da arte, não pode ser compreendido a partir de um exame da técnica ou, finalmente, em função dos testemunhos do próprio Cézanne acerca da sua obra. Esse sentido, se é possível determinar um sentido universal, só encontra testemunho na própria obra que, por sua vez, explica a condição de enraizamento do sujeito no mundo. Os primeiros quadros de Cézanne - a sua primeira fase até 1870 - observa Merleau-Ponty, são sonhos pintados (ex: O rapto) ${ }^{4}$; ele quer pintar o interior, "a fisionomia moral dos gestos." (MERLEAU-PONTY 2004c, p. 125) Na segunda fase da sua pintura, na companhia do pintor Pissaro, Cézanne encontra a estética impressionista e se volta para o exterior, nesse momento todos os motivos da pintura são dados pela contemplação da natureza. A terceira fase, marcada pela separação do impressionismo, supõe uma volta não ao objeto, não à paisagem, mas um retorno às coisas mesmas que figuram no campo da visão. Nessa última fase, o objetivo de Cézanne é pintar as coisas na sua mais pura integridade, pintar a sua solidez, as suas cores, a sua carne e todos os índices que as 
tornam presenças visíveis. Agora, interior e exterior estão envolvidos em uma única camada: a textura do visível. Assim, conforme a interpretação de Merleau-Ponty, Cézanne pintava pessoas como coisas, pois para poder pintar as próprias coisas - o mundo natural - foi preciso ver as coisas e as pessoas através dos signos universais da visibilidade. Não se trata de destituir o modelo de sua humanidade - como está dado no retrato da Senhora Cézanne ${ }^{5}$ - mas de integrar à humanidade ao tecido original das coisas: "Sua extrema atenção à natureza, à cor, o caráter inumano de sua pintura (ele dizia que se deve pintar um rosto como um objeto), sua devoção ao mundo visível não seriam senão uma fuga ao mundo humano, a alienação de sua humanidade.” (MERLEAU-PONTY 2004c, p.125)

Essa filiação ao primeiro dado, ao sentido primitivo, permite a Merleau-Ponty aproximar a vida engajada do pintor com a experiência do filósofo fenomenológico voltada para a descrição da percepção. Em $A$ Dúvida de Cézanne essa aproximação é quase identificação total, como se os signos expressivos da filosofia e da pintura fizessem parte de uma mesma língua e o enraizamento do pintor e do filósofo compartilhassem a mesma situação, a mesma liberdade. Se "a liberdade é uma retomada criadora daquilo que nós somos.” (MERLEAU-PONTY 2004c, p.141), a pintura - semelhante as nossas escolhas - é a realização em absoluto da liberdade, na medida em que a história pessoal, a história da pintura, a técnica, os motivos do mundo e a situação do pintor são sempre retomados em direção a um projeto maior e inacabado que se apresenta na forma da obra de arte.

Em A Linguagem indireta e as vozes do silêncio, Merleau-Ponty também aproxima a condição do pintor à do filósofo. Operação do escritor não é diferente do pintor: situação e liberdade. Na pintura o processo de criação supõe o pintor situado, num tempo e numa visão de homem. Agora o exemplo não é apenas Cézanne, pois é possível encontrar esses mesmos dados também em Matisse:

(...) olhar o conjunto aberto de sua tela começada e levou o pincel para o traçado que o chamava.... Tudo se passou no mundo humano do gesto e da percepção.... entretanto, é verdade que a mão de Matisse hesitou, é verdade que houve escolha formuladas somente por Matisse que não estavam definidas e formuladas senão de fazer aquele quadro que ainda não existia. (MERLEAU-PONTY 2004b, p.79) 


\section{6}

Para Merleau-Ponty o pintor coloca no quadro um sentir que é seu, mas em última instância, como já está dito acima, um sentir que não pode ser reduzido a nenhum índice psicológico, que deve ser explicado, sobretudo, pela sua condição no mundo: uma existência transgressora sempre capaz de retomar o conteúdo latente e a situação presente e transformá-los e pintura. Portanto, a pintura é reveladora da condição criadora e expressiva de uma existência plena da liberdade. Mesmo considerando que todo pintor tenha diante si uma tradição e uma técnica estabelecidas, ele sempre deve conquistar a sua técnica em suas próprias tentativas. Depois, admitindo que o pintor encontre a significação da sua pintura em obras de outros pintores, ele ainda permanece no domínio da sua liberdade, pois ele "é dotado de um esquema interior que o orienta a ir mais longe”. (MERLEAU-PONTY 2004b, p.83). Esse "esquema interior" explica, também, o estilo do pintor como algo que nasce da obra e não como o conhecimento prévio que se impõe à obra como uma razão constituinte. $\mathrm{O}$ quadro e o estilo brotam da potência criadora do pintor, porém, o quadro se antecipa ao estilo. Merleau-Ponty fala em um sentido operante e latente liberado pela pintura e acessível aos outros: "o estilo, antes de ser oficializado pelo Museu como aquilo que resulta do quadro, diz Merleau-Ponty, vivia em cada pintor como a pulsação do seu coração." (MERLEAU-PONTY 2004b, p.94). Contra ideia de Malraux de que o estilo é o meio pessoal de recriação do mundo, o traço que resulta de uma visão vinculada a uma determinada perspectiva humana, Merleau-Ponty opõe a noção de estilo como visão que "nasce como que a sua revelia", como uma exigência da própria pintura, pois é a obra que explica vida e, também, faz nascer o estilo. $\mathrm{O}$ pintor não reproduz um dado, um sentimento, um costume, objetos, ou a própria natureza armado de um olhar de sobrevoo. No quadro está esboçado um entrecruzamento entre os dados do mundo e a potência inventiva do pintor. O quadro, revelador de todos os elementos da percepção, nasce do mundo, da natureza, da tradição, do enraizamento e da liberdade do pintor no mundo: é "o emblema de uma maneira de habitar o mundo". (MERLEAU-PONTY 2004b, p.84) O estilo, muito além de uma técnica que pré-existe à obra, é o índice da deformação, da retomada de uma visão criadora. A visão secreta do pintor, como interpreta Merleau-Ponty a partir de Malraux, 
encontra na paisagem, em cada pedaço do visível, uma maneira geral de expressar o ser: "Assim Renoir podia olhar para mar, como observa Malraux, é pintar o regato das Lavadeiras". (MERLEAU-PONTY 2004b, p.85) A liberdade, nesse sentido, está em ver na paisagem, na natureza e nos museus todos os signos da visibilidade.

Em A linguagem indireta e as vozes do silêncio, Merleau-Ponty aprofunda o papel do corpo no processo de criação do pintor em relação as suas afirmações estabelecidas em $A$ Dúvida de Cézanne. O pintor conta com o esquema corporal - olhar e as mãos fenomênicas - que se dirige ao mundo e a tela. O corpo vê e transforma o mundo em pintura, coloca em tudo uma unidade que pode ser reconhecida como um "estilo humano”. Desse modo, a unidade da pintura de Cézanne não está na reunião de uma razão suprassensível ou na análise da sua vida individual, mas no poder que o corpo tem de impor o seu estilo em tudo o que faz. Merleau-Ponty reconhece o estilo e a unidade da pintura como expressões que nascem da reelaboração do corpo próprio dos dados da natureza, da história e da cultura: “... é a operação expressiva do corpo, iniciada pela menor percepção, que se amplifica em pintura e em arte. $\mathrm{O}$ campo das significações picturais está aberto desde que surgiu um homem no mundo. E o primeiro desenho nas paredes das cavernas somente fundava uma tradição porque retinha outra: a da percepção”. (MERLEAU-PONTY 2004b, p.102)

O pintor, pela própria necessidade da sua arte, por jamais recusar a sua visão das coisas, ocupa uma posição no mundo e, por isso mesmo, nunca será traído por um olhar de sobrevoo. Ele está no tecido do espetáculo, não fala fora do mundo, pois ele não fala, mas surge do mundo com um duplo aparelho carnal: os olhos e as mãos. Nesse sentido, o pintor é como um fenomenólogo genético, mas com a vantagem de expressar ao corpo - falar aos olhos - o mundo que é dado na sua experiência direta e sensível. A filosofia que anima o trabalho do pintor, conforme a interpretação merleau-pontyana, não é comparável ao realismo empírico ou ao idealismo transcendental, é uma filosofia assentada na reflexão corporal do ser no mundo. Além do mais, a pintura não é imitação, é expressão do sentir. Quando Cézanne afirmava que o Museu do Louvre era o livro aberto que todos os pintores deviam consultar, ele também dizia, insistentemente, que só podemos pintar colocando no 


\section{8}

quadro a nossa força expressiva, o nosso próprio gênio. Isso fica claro nas releituras de Cézanne das obras de Manet como, por exemplo, em "Uma Olímpia Moderna"6.

Todavia, em O Olho e o espírito Merleau-Ponty marca uma distinção entre a potência expressiva da pintura e o discurso filosófico. Diferente dos textos anteriores, existe uma especificidade da pintura em relação à Filosofia e à Literatura, explicada, sobretudo, pela situação do pintor diante do mundo, pela consciência do esquema carnal e pela força expressiva da linguagem figurativa da pintura. Essa presença carnal no mundo, essa comunicação vivida no próprio corpo é o que permite ao pintor recuar ao sentido primário das coisas, realizar o movimento prospectivo mais radical do projeto do filósofo fenomenológico. Pois na pintura, a partir da apresentação - descrição - dos índices brutos do visível, todas as fronteiras entre o eu, o outro e as coisas estão suprimidas.

Primeiro, estabelece Merleau-Ponty, o filósofo e o escritor não podem colocar o mundo em suspensão, não podem se ausentar da vida prática: "eles não podem designar da responsabilidade do homem que fala." (MERLEAU-PONTY 2004a, p.15) A literatura e a filosofia são artes políticas, e os filósofos, principalmente em função de uma tradição que remonta a Sócrates, devem buscar respostas para o seu tempo, para as crises da sociedade política.Vale para o filósofo, nesse caso, a máxima de Husserl: “O filósofo é um funcionário da humanidade." Em função dessa necessidade, dessa impossibilidade de ausência nasce o risco do pensamento operatório, da produção de ensaios mediados pela urgência de um pensamento que se coloca na superficie da historicidade. Já o pintor é livre para meditar sobre as formas do visível e recusar uma vida politicamente engajada. O seu único compromisso é com a sua obra de arte, com o mundo que figura no seu campo visual.

Contudo, não é a possibilidade de uma ausência política que explica "a ciência secreta" do pintor. A liberdade está, antes de tudo, na abertura do olhar, na não obrigação de ver as coisas julgando-as. Pensamento operatório, pensamento de sobrevoo, pensamento de objeto em geral, visão técnica são opções para o pintor; e ele é sempre livre para recusá-las em direção a um pensamento enraizado no trabalho do mundo sensível e na vida do corpo. Livre de determinações, soberano a partir da sua visão, o pintor pode olhar todas as coisas sem nenhum dever de apreciação: 
Ele está ali, forte ou fraco na vida, mas incontestavelmente soberano em sua ruminação do mundo, sem outra técnica senão a que seus olhos e suas mãos oferecem à força de ver, à força de pintar, obstinado em tirar desse mundo, onde soam os escândalos e as glórias da história, telas que pouco assentarão às cóleras e às esperanças dos homens, e ninguém murmura. (MERLEAU-PONTY 2004a, p.15)

O pintor emprega o corpo próprio sem intermediações. Entre o mundo e corpo existe imbricação carnal, ambos são visíveis, táteis e estão em movimento. A natureza dessa imbricação, anunciada na Fenomenologia da percepção por meio de uma análise da mão que toca e da mão tocada é retomada em $O$ Olho e o espírito e ampliada em direção ao mundo sensível. Na Fenomenologia da percepção, como já está estabelecido, essa experiência foi usada para mostrar como o corpo próprio é capaz de uma espécie de reflexão e, por isso mesmo, diferente de uma filosofia mecanicista, não pode ser tomado como um objeto. Em O Olho e o espírito, na análise da experiência do pintor, a reversibilidade manifesta uma nova possibilidade; é alargada para o todo corpo; da mão para o olho, do tocar para o ver. A reversibilidade é o quiasma - o entrecruzamento - entre o corpo e a carne do visível. O corpo do pintor é um vidente-visível, ele olha e participa do mundo. Toda a filosofia do pintor - a expressão pictural que está na sua obra - nasce da visão e explica a experiência da reversibilidade, pois o artista não se distingue entre ver as coisas e ser visto por elas. A potência motora do corpo e a sua ligação carnal com o mundo, encontram na pintura a sua fórmula mais profunda. A pintura é um gesto corporal, nasce do próprio corpo, da visão e das mãos do pintor. A experiência da pintura nos releva que entre o corpo e o mundo, nas palavras de MerleauPonty, “existe transubstanciação.” (MERLEAU-PONTY 2004, p. 17)

O entrelaçamento do corpo com mundo é uma operação da visão que nasce e explica a nossa condição sentiente-sentido. Todos os problemas da pintura, diz Merleau-Ponty, estão dados nessa relação, uma verdadeira comunhão entre o corpo e o mundo. Todavia, essa operação não é material, não é da ordem da coisa-objeto, mas das modulações sensíveis que conferem visibilidade ao visível: qualidade, luz, cor, profundidade etc. Todos esses índices da visibilidade, não estão no sujeito, não nascem da consciência, não são uma ilusão de ótica, não estão presos às 
coisas ou limitados ao corpo próprio. Esses emblemas da visibilidade se comunicam com o corpo que os acolhe e, também, se faz visível por meio deles. Esse equivalente interno, essa meditação carnal de uma dupla presença, também desperta um rastro de visibilidade que une um corpo ao outro; realiza a comunhão entre duas visões e tem o poder de fazer com que um outro olhar reencontre os mesmo motivos que sustentam uma inspeção pessoal do mundo. A visão, portanto, é movimento de encontro entre o vidente e o visível. No emprego do olho e da mão, o pintor nunca se apropria da natureza, no máximo, realiza uma reintegração entre aquele que vê e aquele que é visto.

Visível e móvel, meu corpo conta-se entre as coisas, é uma delas, está preso no tecido do mundo, e sua coesão é de uma coisa. Mas, dado que se vê e se move, ele mantém as coisas em círculo ao seu redor, ela são um anexo ou um prolongamento dele mesmo, e o mundo é feito do mesmo estofo do corpo. (MERLEAU-PONTY 2004a, p.17)

Em O Olho e o Espírito várias páginas são dedicadas para explicar a diferença entre dois modelos de visão: o cartesiano e o fenomenológico, retratado, sobretudo, na experiência do pintor: "há a visão sobre o qual reflito, (...) E há a visão que se efetua, pensamento honorário ou instituído (...), a ordem autônoma do composto de alma e corpo." (MERLEAU-PONTY 2004a, p.31)

Partindo de hipóteses semelhantes aos princípios que originaram a teoria dos reflexos condicionados, o cartesianismo sustenta duas ideias básicas acerca da visão: é constituída partes por partes e é destituída de sentido próprio. Na primeira situação, o modelo cartesiano da visão é retratado a partir de uma concepção linear do tato. A visão é o resultado de conexões causais nervosas e óticas. Esse "pensamento honorário" está fundado em um viés atomista; em uma geometria unidimensional de raios e luzes. Contudo, além disso, sustenta Merleau-Ponty, para o cartesianismo a visão em si mesma não oferece nenhum significado, pois a verdade da visão é sempre posterior ao ato de ver e deve ser procurada no pensamento. Para Descartes, como encontramos em diferentes passagens da Dioptrica e das Meditações Metafísicas, dirigir os olhos para a paisagem é tão somente responder aos estímulos óticos que atingem o órgão sensitivo. A visão não se realiza no olho e, também, não está no ato olhar. Para 
Descartes, o olho, em si mesmo, é estéril. A visão das coisas mesmas resulta do intelecto, de uma ação do pensamento que supre a aridez criadora e perceptual do olho, como podemos ler no texto da segunda Meditação:

(...) se por acaso não olhasse pela janela homens que passam pela rua, à vista dos quais não deixo de dizer que vejo homens da mesma maneira que digo que vejo a cera; e, entretanto, que vejo desta janela, senão chapéus e casacos que podem cobrir espectros ou homens fictícios que se movem apenas por molas? Mas julgo que são homens verdadeiros e assim compreendo, somente pelo poder de julgar que reside em meu espírito, aquilo que acreditava ver com meus olhos. (DESCARTES 1991, p.179)

Para Merleau-Ponty, a visão - sobretudo, "a visão em ato" - ignorada pelo cartesianismo, realiza a prospecção do mundo sensível. A visão é a reflexão carnal em situação, é o contato do corpo próprio com o espaço bruto, com a luz natural, com as coisas em seu estado nascente. A visão tem o poder fundamental de manifestar, de alcançar a textura da visibilidade: "A visão é o encontro, como uma encruzilhada, de todos os aspectos do ser." (MERLEAU-PONTY 2004a, p. 44) Nesse sentido, todas as questões da pintura e da própria fenomenologia figuram no fenômeno da visão: o que é a profundidade, o que é a luz, o que é espaço, o que são as coisas, o que é outro etc. Além do mais, esse poder da visão de se alojar no pré-reflexivo, na camada anterior a todas as abstrações faz com que o nosso corpo seja ao mesmo tempo vidente e visível. $\mathrm{Na}$ visão em ato, o corpo próprio invade as coisas, domina os segredos do visível, como, também, é invadido, é visto pelas coisas. O corpo, através da visão, tem esse poder de ver e ser visto, de ser carne e participar da carne do mundo:

Um corpo humano está aí quando, entre vidente e visível, entre tocante e tocado, entre um olho e outro, entre a mão e a mão se produz uma espécie de recruzamento, quando se ascende a fásca do sentiente-sensível, quando se inflama o que não cessará de queimar, até que um acidente do corpo desfaça o que nenhum acidente teria bastado para fazer..." (MERLEAU-PONTY 2004a, p.18)

No Visivel e o invisivel, Merleau-Ponty aponta para os limites da fenomenologia ao sustentar a ideia de que descrever a nossa experiência percep- 
tiva não é a mesma coisa que experimentá-la. Enquanto toda a reflexão sobre o irrefletido é um abandono do irrefletido, a pintura, num sentido diverso, é criação e manifestação da experiência do irrefletido.

Merleau-Ponty encontra na arte - mais especificamente na pintura uma descrição do mundo sem o abandono da nossa experiência originária. A pintura, essa meditação profunda sobre a potência da visão, realiza uma descrição do sentido bruto das coisas que parece impossível para a filosofia, mesmo para uma onto-fenomenologia. A experiência da pintura, livre de convenções e de teses, unicamente ancorada na potência perceptiva e criadora da visão, permite o encontro do sentido do ser - da estrutura do real - que escapa a toda reflexão filosófica. O quadro, como deveria ser um texto filosófico, é o testemunho de uma linguagem muda capaz de expressar a nossa iniciação ao mundo.

A potência reveladora nascida da pintura, privilegiada na análise da obra de Cézanne, explica o sentido do ser no mundo. A pintura resulta da experiência perceptível vivida na relação que o corpo próprio mantém com o mundo natural e com os outros no interior do horizonte global do ser no mundo. Na experiência estética, como é o caso de Cézanne, o pintor quer voltar ao objeto primordial, ao elemento primeiro da natureza e pintar as coisas mesmas. A linguagem da pintura, o conjunto representativo da cor, da linha, da textura e do desenho compõe uma força expressiva capaz de comunicar como as coisas são podem ser expressas. A pintura é sinestésica, é entrecruzamento de todos os sentidos e técnicas e - como interpreta Merleau-Ponty em uma nota de trabalho de outubro de 1959 - realiza o projeto alcançar e expressar a vida irrefletida sem traí-la, sem se ausentar dela:

(...)Então o ato de desenhar e de pintar, - o ato de pintar como em si mesmo - e de pintar como outro isolam-se um do outro e não se vê mais relação entre eles.Vê-la-íamos, pelo contrário, se compreendêssemos que pintar, desenhar não é produzir algo a partir de coisa nenhuma, que o traço, a pincelada e a obra visível não são senão o vestígio de um movimento total da Fala, que conduz ao Ser na sua totalidade e que esse movimento abarca tanto a expressão pelos traços quanto a expressão pelas cores, tanto a minha expressão como a dos outros pintores."(MERLEAU-PONTY 2000, p.197). 
Em O Olho e o espírito, a pintura livre da necessidade de descrever, expressa não o visível, mas a camada que faz o visível visível. Cézanne não pinta a montanha de Santa Vitória procurando realizar uma cópia ou, ainda, representar uma experiência individual, o modo particular como a montanha foi vista. O que ele busca é expressar aquilo que permite a montanha ser vista como tal: a luz, as cores, as formas, a composição, o espaço, a sua carne. A pintura, não apenas a moderna ou a obra de Cézanne, nasceu dessa vibração, dessa irradiação que o ato ver produz. Todos os problemas, todos os segredos da pintura consistem em decifrar o enigma da visão. Tudo o que aparece ao olhar do pintor, tudo o que ele interroga por meio da sua visão ele converte em quadro. A ciência secreta do pintor - animada pela potência criativa do olho e das mãos, signo da liberdade como poder recriação - é o paradigma de uma onto-fenomenologia que encontramos nas últimas tentativas da filosofia merleaupontyana: a linguagem bruta que permite expressar a textura do ser.

A pintura, como está dada em $O$ Olho e o espírito, enquanto interroga o logos da visibilidade é uma apresentação não conceitual do Ser universal. Pois como uma ciência secreta e silenciosa e, ao mesmo tempo, tátil e visível, a pintura, sobretudo a moderna, abdica dos signos do pensamento objetivo - das palavras e dos números - para permitir a fala figurativa do vidente e a manifestação dos índices - signos - do visível: as linhas, as cores, o movimento, a profundidade etc. A linha oculta das pinturas impressionista e moderna, interpreta Merleau-Ponty, ultrapassa a concepção ordinária de linha - "atributo positivo e propriedade do objeto em si” (MERLEAU-PONTY M-P, 2004a, p.38) - e, ao mesmo tempo, é reveladora da experiência enigmática da visão, como foi anunciado em o Visível e o invisível: "Qual a razão por que envolvendo-os meu olhar não os esconde e, enfim, velando-os não os desvela? (MERLEAUPONTY, 2000, p.128)

Para pintores como Klee ${ }^{7}$ e Matisse ${ }^{8}$, por exemplo, a linha está na pintura não como contorno ou fronteira do visível, mas tem o sentido de uma tessitura acoplada ao ser das coisas, ao tecido que une o visível e o vidente. Do mesmo modo a visão, como as linhas das obras de Klee, envolve e veste as coisas, cobre e, na mesma situação, descobre as coisas: "Figurativa ou não, a linha em todo caso não é mais imitação das coisas nem coisa. É um certo desequilíbrio disposto na indiferença do papel em 


\section{4}

branco, é uma certa perfuração praticada no em-si, um certo vazio constituinte...( MERLEAU-PONTY, 2004a, p.38). Voltamos aqui ao texto inicial desse trabalho, a análise do campo de futebol da Estrutura do Comportamento. Entre o corpo do jogador e o campo de futebol opera uma relação de entrecruzamento de linhas e espaços vazios. $\mathrm{O}$ jogador e as linhas do campo formam uma estrutura sentiente-sentido, onde os signos da espacialidade - direção, distância, altura, profundidade - permanecem, ambiguamente, definidos e abertos, são vividos no corpo e, ao mesmo tempo, encontrados no campo. O corpo está no campo assim "como o coração está organismo." Como a linha não é simplesmente contorno, mas é um sistema vivido no corpo e formado no campo, ela alonga e limita o espetáculo (desloca o espaço e move o corpo), está e não está na fronteira que reúne o visível ao vidente. Já a visão, de modo paradigmático, não é fundada no visível e nem o visível penetra no olho. A visão é essa linha nauseante - meio entre o sentiente e o sensível - que ultrapassa todas as clivagens que separam o corpo do mundo, o sujeito do objeto, a essência da existência. A expressão pictural, fundada nessa familiaridade entre o corpo e o mundo, realiza e expressa o encontro de todos os índices da visibilidade e, desse modo, nos desperta para o poder da visão de espelhar e recriar a partir de um único olhar todas as faces do ser. Poder que podemos ver, conforme nos indicam as sensíveis palavras de Rilke, no autorretrato de Cézanne9: "E como é grande e inabalável esta objetividade do seu contemplar! É o que se confirma de uma maneira quase comovente pela situação, por ele ter reproduzido a si mesmo sem mesmo a mais remota tentativa de interpretar sua expressão, sem vê-la presunçosamente, e com tão humilde objetividade, com a fé e a participação interessada e objetiva de um cachorro, que se vê no espelho e pensa: aí está outro cachorro .” (RILKE, Cartas sobre Cézanne, p. 88).

\footnotetext{
${ }^{1}$ Ex: "the man I Love; L'homme que j'aime".

${ }^{2}$ Merleau-Ponty escreveu três ensaios que abordam diretamente o tema da pintura.A Dúvida de Cézanne - escrito do primeiro período da sua obra, portanto ainda nos anos 40 -; A linguagem indireta e vozes do silêncio - da fase intermediária nos anos 50 -; e O Olho e o espírito, último texto publicado em vida pelo autor, em 1960.
} 
${ }^{3}$ Moutinho, na sua obra Razão e experiência. Ensaio sobre Merleau-Ponty, discute a relação entre os textos estéticos de Merleau-Ponty - sobretudo a Dúvida de Cézanne e A Linguagem Indireta - e o desenvolvimento da filosofia merleau-pontyana; fundamentalmente o momento da passagem da experiência perceptiva para uma consideração genética. Conforme Moutinho, na Linguagem Indireta a pintura é tratada como filosofia, expediente que permitiu a MerleauPonty ultrapassar a teoria da expressão formulada conjuntamente na Fenomenologia da Percepção e na Dúvida de Cézanne: "Gostaria de mostrar aqui, tomando o caso específico da pintura, que a abordagem desse tema já consagra o esforço de Merleau-Ponty em realizar o ultrapassamento da vida da percepção." (Moutinho, 2006, p. 341)

4 Conf. Cézanne. Abduction. (1867) Technique Huile sur toile 90x117cm. Exposé à Cambridge (Angleterre) au Université de Cambridge

5 Conf. Cézanne. Madame Cézanne dans la Serre (1892) Technique Huile sur toile 92x73cm.. Exposé à New York (USA) au Metropolitan Museum of Art.

${ }^{6}$ Conf. Cézanne. Une Olympia moderne (1873). Technique Huile sur toile 46x55cm Exposé à Paris (France) au Musée d'Orsay.

7 Conf. Paul Klee. Heroic Roses. 1938. Oil on stained canvas. 68 x 52 cm. Kunstsammlung Nordrhein-Westfalen, Düsseldorf, Germany

8 Conf. Henri Matisse. Large Red Interior. 1848. Oil on canvas. Musée National d'Art Moderne, Centre Georges Pompidou, Paris, France.

${ }^{9}$ Conf. Cézzane. Autoportrait. (1875). Technique Huile sur toile de tilleul 64x53cm . Exposé à Paris (France) au Musée d'Orsay.

\section{Referências bibliográficas}

BARBARAS, Renaud. Les trois sens de la chair. Sur une impasse de l'ontologie de Merleau-Ponty. Iin Chiasmi International, $\mathrm{n}^{\circ} 10$, 2008, pp. 19-34.

CARBONE, Mauro. La visibilité de l'invisible. Merleau-Ponty entre Cézanne et Proust. Hildesheim-Zürich-New-York: OLMS, 2001.

DESCARTES, René. Discurso do Método (a); As paixões da alma (b); Meditações Metafísicas (c); Objeções e Respostas (d). 5 ed. In: Os

Pensadores. São Paulo: Nova Cultural, 1991.

KANT, Immanuel. Crítica da Faculdade do juízo. 2a edição. Rio de Janeiro: Forense Universitária, 2002.

MERLEAU-PONTY, Maurice. La Structure du comportement. Paris: Presses Universitaires de France,1972. 
Fenomenologia da percepção. 2. ed. São Paulo: M. Fontes, 1999.

. O visível e o invisível. 4. ed. São Paulo: Perspectiva, 2000.

O Olho e o Espirito (a); A Linguagem Indireta e as Vozes do Silêncio (b); A dúvida de Cézanne (c). Cosac \& Naify, São Paulo, 2004. . Signes. Paris: Gallimard, 1960. . Le visible et l'invisible. Paris: Gallimard, 1964. [Links] . Résumés de cours: Collège de France (1952-1960). Paris:

Gallimard, 1968. La nature. Paris: Seuil, 1995.

MOUTINHO, L. D. Razão e experiência. Ensaio sobre Merleau-Ponty. $1^{a}$. ed. São Paulo: Editora UNESP, 2006.

RILKE, M.R. Cartas sobre Cézanne. Rio de Janeiro: 7 Letras, 2006. 